\title{
The role of PI3K signaling pathway and its associated genes in papillary thyroid cancer
}

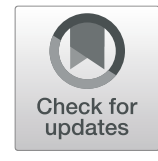

Elham Amjad ${ }^{\dagger}$, Solmaz Asnaashari ${ }^{\dagger}$ and Babak Sokouti ${ }^{*}$

\begin{abstract}
Background: One of the well-differentiated types of thyroid cancer is papillary thyroid cancer (PTC), often developed by genetic mutations and radiation.

Methods: In this study, the public NCBI-GEO database was systematically searched. The eligible datasets were the targets for biomarker discovery associated with PI3K signaling pathway.

Results: Only two datasets were suitable and passed the inclusion criteria. The meta-analysis outcomes revealed eleven upregulation and thirteen downregulation genes differentially expressed between PTC and healthy tissues. Moreover, the outcomes for survival and disease-free rates for each gene were illustrated.
\end{abstract}

Conclusions: The present research suggests a panel signature of 24 gene biomarkers in diagnosing the PTC.

Keywords: Papillary thyroid cancer, Meta-analysis, GEO datasets, Signaling pathway, Biomarker

\section{Background}

Papillary thyroid cancer (PTC), as one of the most prevalent cancer types diagnosed in the thyroid gland, covers more than $85 \%$ of total thyroid cancers $[1,2]$. According to the fact that most of the large followed up thyroid cancer studies, specifically PTC, are epidemically carried out in the US nations, there are very few data available for monitoring the incidence of PTC worldwide [2]. Moreover, the well-known Surveillance, Epidemiology, and End Results database (SEER13) showed that the 5-year relative survival rate for 2010-2016 in the USA was $98.3 \%$ through age-adjusted incident rate with an unchanged trend for mortality rate of $0.4-0.5 \%$ [3]. Additionally, the Korean literature report indicated that the recurrence rate of patients with PTC after surgical treatment was less than $15 \%$ which led to survival by about $65 \%$ without including either 5- or 10-year survival rates [4]. However, various aggressive descriptors determined for PTC disease from imaging techniques

\footnotetext{
*Correspondence: b.sokouti@gmail.com; sokoutib@tbzmed.ac.ir

†Elham Amjad and Solmaz Asnaashari are co-first authors.

'Elham Amjad and Solmaz Asnaashari contributed equally to this work.

Biotechnology Research Center, Tabriz University of Medical Sciences, Tabriz, Iran
}

(c) The Author(s). 2021 Open Access This article is licensed under a Creative Commons Attribution 4.0 International License, which permits use, sharing, adaptation, distribution and reproduction in any medium or format, as long as you give appropriate credit to the original author(s) and the source, provide a link to the Creative Commons licence, and indicate if changes were made. The images or other third party material in this article are included in the article's Creative Commons licence, unless indicated otherwise in a credit line to the material. If material is not included in the article's Creative Commons licence and your intended use is not permitted by statutory regulation or exceeds the permitted use, you will need to obtain permission directly from the copyright holder. To view a copy of this licence, visit http://creativecommons.org/licenses/by/4.0/.

have proposed a weak prognosis [4]. A recent case study reported that even if the diagnosis of PTC is somewhat tricky, combining a set of imaging techniques and fineneedle aspiration would make the road simplifying the PTC diagnosis [5].

The recent advancements in medical sciences have performed well by using microarray technology in narrowing down the list of diseases for diagnosis and prognosis procedures $[6,7]$, and on the other hand, the advances in technology will generate the Big data. In this regard, studying molecular and cellular functions of the particular diseases, e.g., the PTC, at genome-wide levels needs to be of priority. In other words, to differentiate between healthy and unhealthy tissues, the discovery of robust biomarkers is essential, either through experimental and clinical studies or computational biology approaches on Omics datasets [8]. There are several studies on investigating the molecular and physiological mechanisms of activation and inactivation of different signaling pathways having critical roles in the progress of PTC [9]. Since signaling pathways constitute hundreds of components, such as genes responsible for many cellular processes, their biological functions remain unclear and complicated [9]. 
Understanding the complex nature of PTC in terms of the involved signaling pathways urges studying vital roles of associated genes in the PI3K signaling pathway between PTC and healthy patients. For this purpose, the systematic search of the NCBI-GEO database retrieves the results of interest for further analysis and content screening based on inclusion and exclusion criteria. Finally, the genes of the selected GEO datasets will be the targets for identifying the differentially expressed genes among the datasets to be considered as robust biomarkers for PTC disease.

\section{Methods}

\section{Identification of microarray datasets}

The National Center for Biotechnology InformationGene Expression Omnibus (NCBI-GEO) database (i.e., http://www.ncbi.nlm.nih.gov/geo) was the repository source for the systematic search of microarray datasets. For this search, a Boolean query was used, including the keywords "papillary thyroid cancer" or "PTC." Furthermore, a thorough inspection on the search results was necessary for identification and inclusion of those GEO datasets in the analysis which satisfy the following criteria: (i) based on "expression profiling by array," (ii) to be of [9606] organism, (iii) mRNA sample types, (iv) to have both PTC samples and healthy controls, and (v) extracted from the source of thyroid tumor. Notably, any platform types were of interest. Moreover, the excluded GEO datasets were those that not fulfilled the abovementioned inclusion criteria. Accordingly, the final selected GEO datasets with sufficient data were prone to perform a meta-analysis by including the associated genes of the PI3K signaling pathway.

\section{Associated genes for PI3K signaling pathway}

The Kyoto Encyclopedia of Genes and Genomes (KEGG) database (i.e., https://www.genome.jp/kegg/pathway. html) was the resource to derive the involved genes in the PI3K signaling pathway (hsa04151) for Homo sapiens organism. Then, to carry out the meta-analysis approach among the GEO datasets, the associated genes of the PI3K signaling pathway were only considered for this purpose.

\section{Meta-analysis procedure}

The ExAtlas free online tool for the meta-analysis of gene expression datasets possesses several main functions, such as the standard meta-analysis with fixed and random effects, z-score, and Fisher's methods [10]. For this purpose, the input of the ExAtlas website included all GEO datasets meeting the inclusion criteria. However, among the whole gene symbols available in the GEO datasets, only those genes associated with the
PI3K signaling pathway were selected for metaanalysis. The pre-processing stage of the input gene expression datasets comprised $\log 2$ transformation and quantile normalization applied to their corresponding intensity values as well as $t$ test ANOVA analysis. After, a data quality check of the included samples was carried out based on the standard deviation criterion $\mathrm{SD} \leq 0.3$. Finally, the false discovery rate (FDR) and fold change parameters were 0.05 and 2, respectively, for the meta-analysis stage. Due to the heterogeneous nature of the gene expression datasets, the results for the random-effects model would be necessary.

\section{Analyses of survival and relapse-free rates}

In survival analysis, various statistical methodologies analyzed the experimental data of interest in a defined period of follow-up time, usually, 200 months, in which death or relapse could happen carried out by plotting the Kaplan-Meier estimates [11, 12]. In this study, both overall survival (OS) and relapse-free survival (RFS) rates were considered on the Cancer Genome Atlas (TCGA)-THCA database professionally developed for thyroid carcinoma $(n=512)$ against control samples $(n=59)$. The Kaplan-Meier plots were obtainable using the GEPIA2 (http://gepia2. cancer-pku.cn/\#index) web service [13]. In the KM-plot analysis, the $p$-values less than 0.05 were significant for input genes and the preset confidence interval for hazard ratio was $95 \%$.

\section{Results}

The overall results obtained from systematically screening of the NCBI-GEO database, where the data extraction procedure is depicted is Fig. 1, by taking in to account the inclusion and exclusion criteria showed that only two microarray datasets (i.e., GSE29265: 20 Normal and 20 PTC and GSE97001: 4 Normal and 4 PTC) were eligible for meta-analysis procedure. Three hundred fifty-four out of a total of 354 genes involved in the PI3K signaling pathway were selected from the two GEO datasets to identify the significant genes differentially expressed between the two tissue types. The ExAtlas website demonstrated that all of the samples included in the GEO datasets passed the initial quality control, which then was suitable for the meta-analysis process based on a random-effects model due to the existence of possible heterogeneity. The meta-analysis revealed twenty-four genes significantly expressed in terms of $p$-value and FDR parameter between healthy and PTC samples, among which the numbers of upregulated and downregulated genes were eleven and thirteen, respectively, as represented in Fig. 2. 


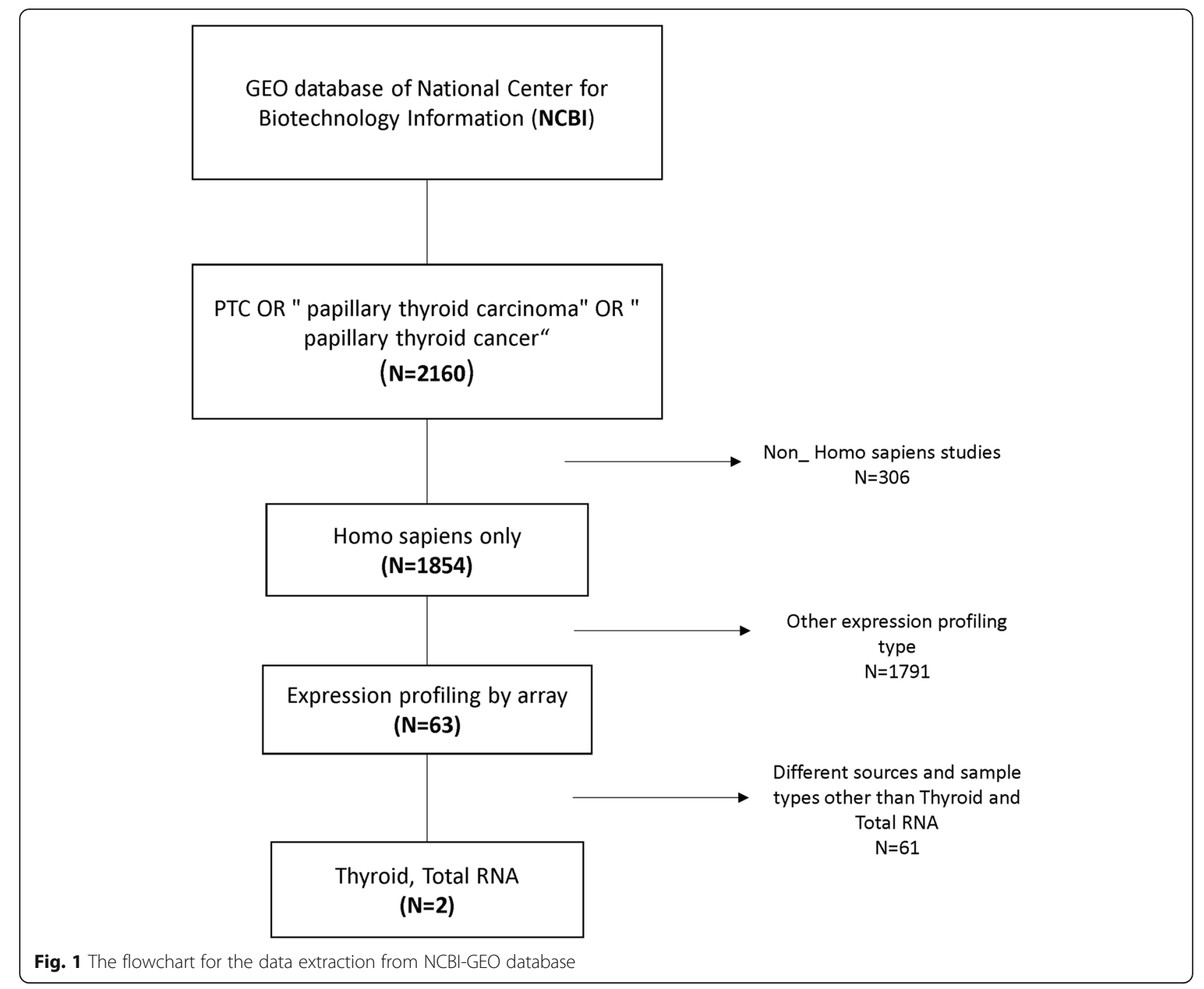

The overall survival (OS) and disease-free rates (RFS) for the identified upregulated and downregulated genes are illustrated in Figs. 3 and 4, respectively. Among upregulated genes, CCND2 was the only significant gene in terms of OS rate with p-value 0.017. Moreover, by considering the downregulated genes, three genes (i.e., GHR $p$-value $=0.0035, \quad$ FGF7 $p$-value $=0.014$, PRKCA $p$-value $=0.045$ ) were found to be significant in terms of OS rate; however, four genes (i.e., KIT $p$-value $=0.012$, GHR $p$-value $=0.016$, PGF $p$-value $=$ 0.05 , FGFR2 $p$-value $=0.029)$ were significant in terms of RFS rate.

\section{Discussion}

Despite the excellent reports on the prognosis of the papillary thyroid carcinoma (PTC) as the predominant form of thyroid cancer, estimating the overall survival of PTC patients has still been remained unknown [15].
In the current research, a meta-analysis approach could demonstrate the significant differentially expressed genes between two GEO datasets meeting the inclusion criteria with $\mathrm{FDR}<0.05$. Avoiding any possible inconsistency between the datasets is critical such that only the GEO datasets with the source of PTC tissues were eligible. In total, 24 genes (11 upregulated and 13 downregulated) were differentially expressed in PTC patients while being compared to the healthy samples with the statistical significance of FDR $<0.05$ and $p$-value $<0.05$ (Table 1 ).

The above-listed genes in Table 1 were thoroughly inspected for their confirmation through various experimental studies considering the neoplastic thyroid disease. The expressions of associated genes in the PI3K signaling pathway were half downregulated and half upregulated. Taking in to account that some studies have reported on the target overexpressed gene whereas in 


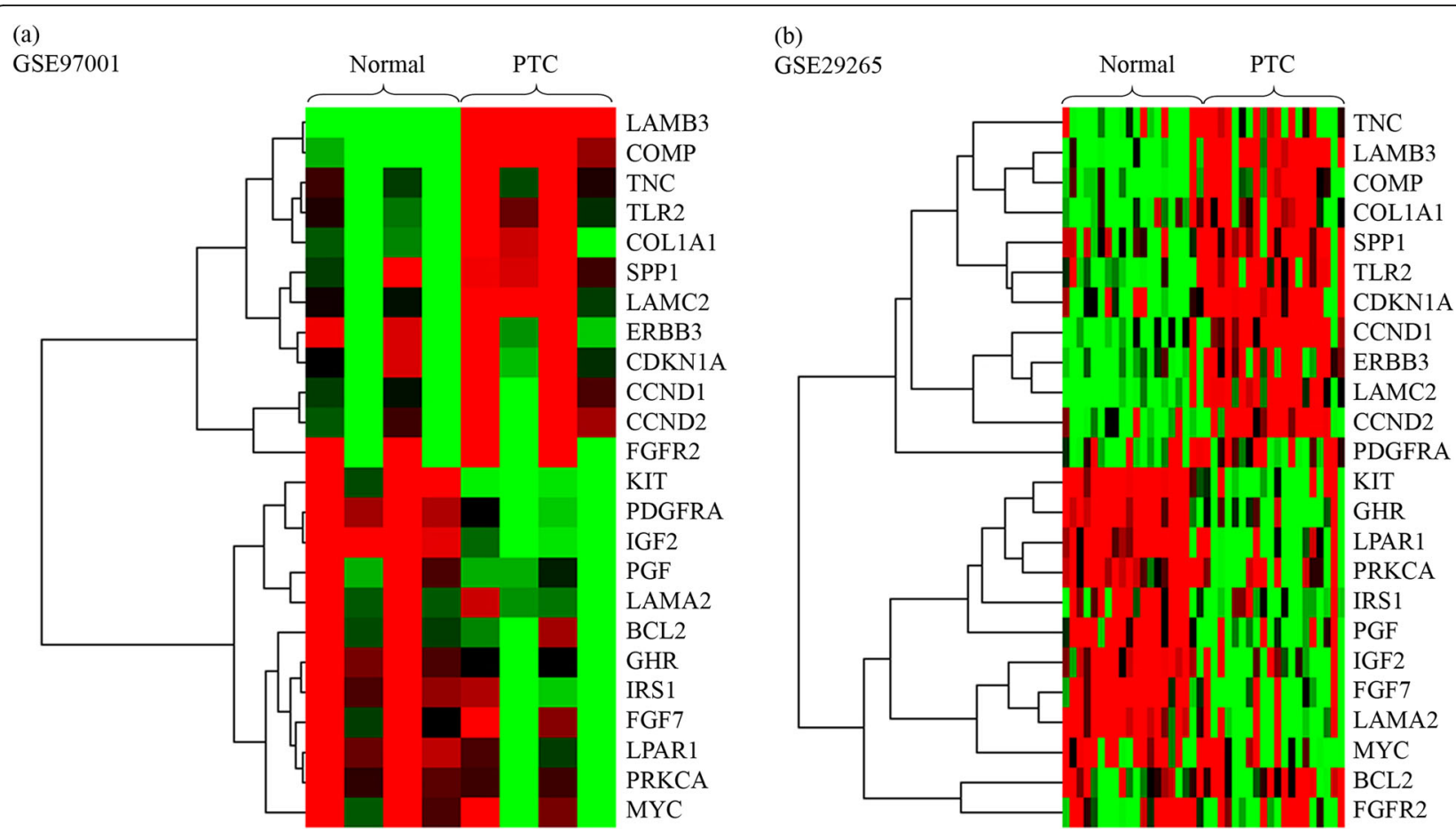

Fig. 2 Cluster analysis of significant genes obtained from the meta-analysis approach for (a) GSE97001 and (b) GSE29265 datasets using Gene Cluster 3.0 and Java TreeView tools [14]. Upregulated genes with fold change combined values: LAMB3 (FC=23.836), COMP (FC= 7.85), SPP1 ( $F C=3.605)$, TNC ( $F C=3.072)$, RBB3 $(F C=2.842), C C N D 1 \quad(F C=2.734), T L R 2 \quad(F C=2.591), C C N D 2(F C=2.475), L A M C 2(F C=2.452)$, CDKN1A (FC=2.25), COL1A1 (FC=2.146); downregulated genes with fold change combined values: KIT ( $F C=9.05)$, PDGFRA (FC=4.126), IGF2 $(F C=3.734), G H R(F C=3.626), B C L 2 \quad(F C=3.114), I R S 1 \quad(F C=3.038)$, LPAR1 $(F C=2.67), F G F 7 \quad(F C=2.362), P G F(F C=2.31), F G F R 2(F C=2.245), P R K C A$ $(F C=2.242)$, LAMA2 $(F C=2.239)$, MYC $(F C=2.025)$

the current study was determined as downregulated, and vice versa, the main reasons for this may generally originate from several points such as viral infections, patients clinical history, treatment status, the source of control samples, the age of patients as well as patients' race to mention a few (e.g., upregulation and downregulation of has-mir-345 in pancreatic cancer [44, 45]). Moreover, in the current meta-analysis study, statistical stages, including data normalization, $t$ test, and ANOVA tests were performed on GEO datasets to compare the PTC and healthy tissues in the same conditions. Due to the error-prone nature of the clinical and experimental trials, several biases (e.g., publication, laboratory, environmental, and user biases) may affect the reported outcomes by the researchers, and hence, the gene expression levels may not be comparable [46]. The determined genes (with $\mathrm{FC}>2$ ) in the current metaanalysis study can be useful in identifying potent biomarkers for future drug design and discovery. Among the identified biomarkers associated with the PI3K signaling pathway, four of them with FC > 4 were LAMB3 (upregulated), COMP (upregulated), KIT (downregulated), and PDGFRA (downregulated). Various studies have also confirmed the vital role of the activation of the PI3K signaling pathway in the progression and development of PTC disease [47, 48]. As described in the "Results" section, seven genes were significant while considering the OS and RFS rates; however, this outcome will not decline the fact that the other remaining biomarkers have vital roles in the development of the PTC disease.

Consequently, in the current meta-analysis research, a total of twenty-four genes associated with the PI3K signaling pathway were identified and thoroughly screened and validated via the experimental literature studies that could propose a panel of potential biomarkers in PTC disease.

\section{Conclusion}

The present study conducted on PTC GEO datasets revealed the significant role of the meta-analysis approach in determining the potential biomarkers for the disease. Eleven upregulated and thirteen downregulated genes were identified and validated through the literature investigations. By performing a meta-analysis study, one may conclude this type of analysis can fill the gaps between the computational and experimental studies; however, due to the existence of possible heterogeneities among the datasets, some of the differentially expressed genes may be missed that may urge novel algorithms to 

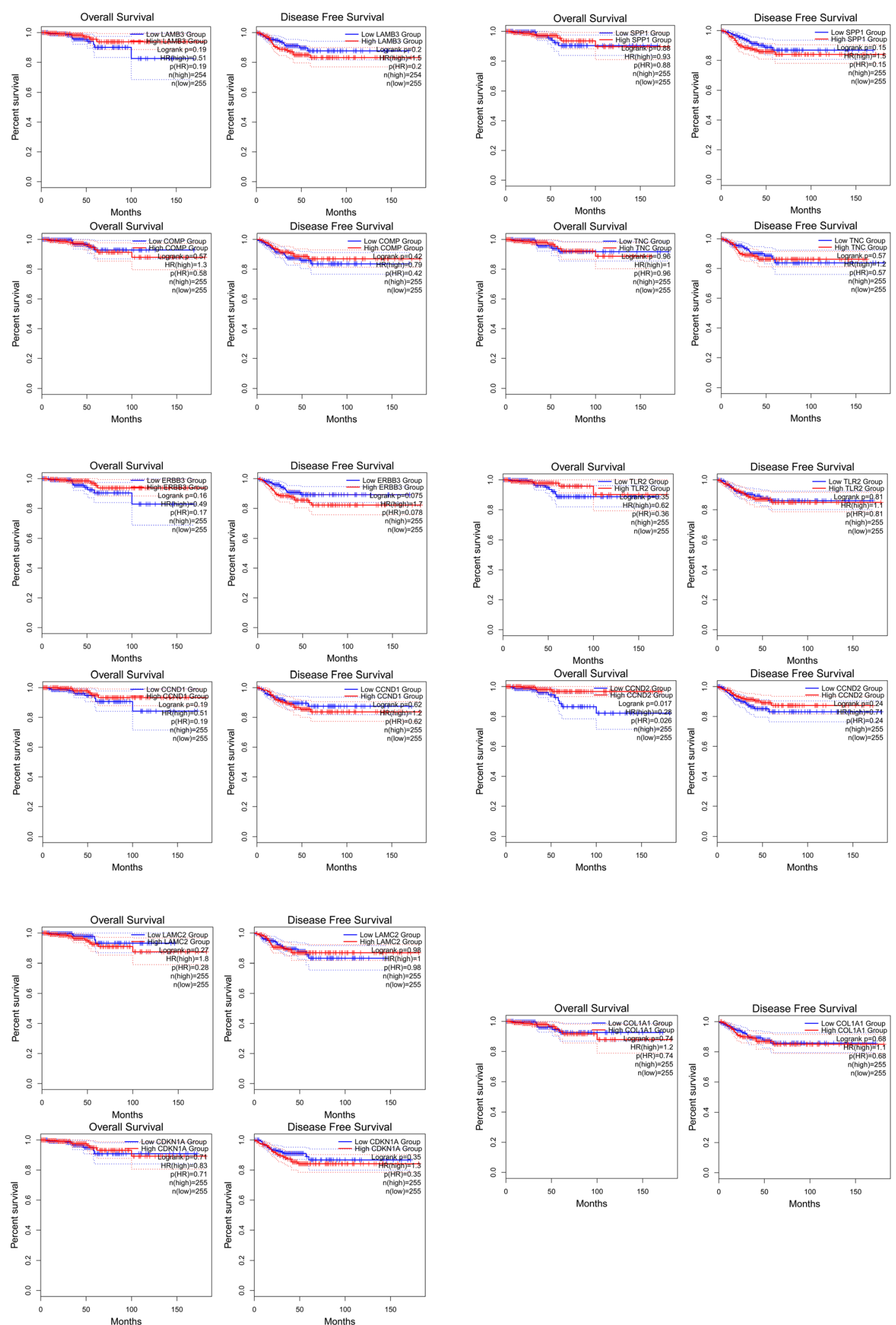

Fig. 3 The survival analyses of identified upregulated genes in terms of OS and RFS 

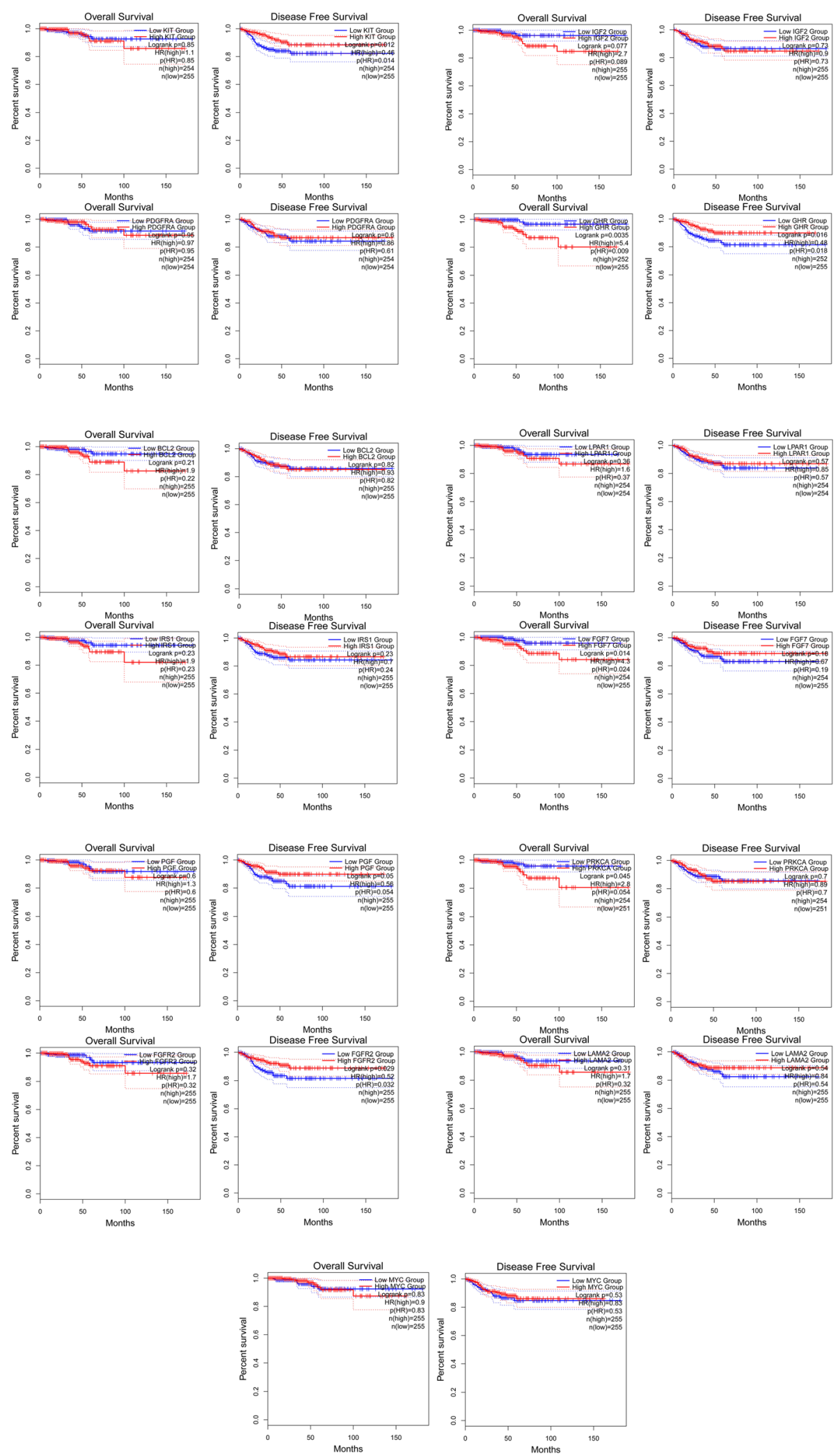

Fig. 4 The survival analyses of identified downregulated genes in terms of OS and RFS 
Table 1 The list of 24 genes consistently expressed differentially between two GEO datasets associated with the PI3K signaling pathways in PTC patients seen in the literature

\begin{tabular}{|c|c|c|c|}
\hline $\begin{array}{l}\text { Gene } \\
\text { symbol }\end{array}$ & $\begin{array}{l}\text { Chromosome } \\
\text { (source: https://www. } \\
\text { genecards.org/) }\end{array}$ & $\begin{array}{l}\text { Disease } \\
\text { (source: https://www.genecards.org/) }\end{array}$ & $\begin{array}{l}\text { References for } \\
\text { associated genes } \\
\text { and PTC }\end{array}$ \\
\hline KIT & $4 q 12$ & $\begin{array}{l}\text { Gastrointestinal stromal tumors (GISTs), melanomas, lung cancer, and other tumor } \\
\text { types }\end{array}$ & {$[16,17]$} \\
\hline PDGFRA & $4 q 12$ & $\begin{array}{l}\text { Idiopathic hypereosinophilic syndrome, somatic and familial gastrointestinal stromal } \\
\text { tumors, and a variety of other cancers }\end{array}$ & {$[18,19]$} \\
\hline IGF2 & $11 p 15.5$ & One of the cancer-related genes & {$[20]$} \\
\hline GHR & $5 p 13.1-p 12$ & Laron syndrome and growth hormone insensitivity, partial & [21] \\
\hline $\mathrm{BCL} 2$ & $18 q 21.33$ & $\begin{array}{l}\text { High grade B cell lymphoma with Myc and/or Bcl2 and/or Bcl6 rearrangement and } \\
\text { follicular lymphoma } 1\end{array}$ & [22] \\
\hline IRS1 & $2 q 36.3$ & Diabetes mellitus, noninsulin-dependent and rare diabetes mellitus type 2 & [23] \\
\hline LPAR1 & $9 q 31.3$ & Pulmonary fibrosis and spinal stenosis & {$[24]$} \\
\hline FGF7 & $15 q 21.2$ & Mucositis and acanthoma & [25] \\
\hline PGF & $14 q 24.3$ & Placental insufficiency and twin-to-twin transfusion syndrome & {$[26]$} \\
\hline FGFR2 & $10 q 26.13$ & Lung and breast cancers & {$[27]$} \\
\hline PRKCA & $17 q 24.2$ & Chordoid glioma and papillary glioneuronal tumors & [28] \\
\hline LAMA2 & $6 q 22.33$ & $\begin{array}{l}\text { Muscular dystrophy, congenital merosin-deficient, 1A and muscular dystrophy, limb- } \\
\text { girdle, autosomal recessive } 23\end{array}$ & [29] \\
\hline MYC & $8 q 24.21$ & $\begin{array}{l}\text { Burkitt lymphoma and high grade B cell lymphoma with Myc and/or Bcl2 and/or Bcl6 } \\
\text { rearrangement }\end{array}$ & [30] \\
\hline LAMB3 & $1 \mathrm{q} 32.2$ & $\begin{array}{l}\text { Epidermolysis bullosa, junctional, Herlitz type, and epidermolysis bullosa, junctional, } \\
\text { non-Herlitz type }\end{array}$ & {$[31]$} \\
\hline COMP & 19p13.11 & Pseudoachondroplasia and epiphyseal dysplasia, multiple, 1 & [32] \\
\hline SPP1 & $4 q 22.1$ & Pediatric systemic lupus erythematosus, and papillary cystadenocarcinoma & [33] \\
\hline TNC & $9 q 33.1$ & $\begin{array}{l}\text { Deafness, autosomal dominant 56, and autosomal dominant non-syndromic sensori- } \\
\text { neural deafness type Dfna }\end{array}$ & {$[34]$} \\
\hline ERBB3 & $12 q 13.2$ & Lethal congenital contracture syndrome 2 and erythroleukemia, familial & {$[35,36]$} \\
\hline CCND1 & $11 q 13.3$ & Von Hippel-Lindau syndrome and myeloma, multiple & {$[37]$} \\
\hline TLR2 & $4 q 31.3$ & Leprosy 3 and colorectal cancer & [38] \\
\hline CCND2 & $12 p 13.32$ & Megalencephaly-polymicrogyria-polydactyly-hydrocephalus syndrome 3 & [39] \\
\hline LAMC2 & $1 \mathrm{q} 25.3$ & Epidermolysis bullosa, junctional, Herlitz type, and epidermolysis bullosa & [40] \\
\hline CDKN1A & $6 \mathrm{p} 21.2$ & Multiple endocrine neoplasia, type I, and tongue cancer & [41] \\
\hline COL1A1 & $17 q 21.33$ & Caffey disease and osteogenesis imperfecta, type I & {$[42,43]$} \\
\hline
\end{tabular}

cover the shortcomings. The biomarker discovery is one of the hot topics in the field, which still needs more advancements in terms of technical, experimental, and computational designs to achieve more robust and reliable biomarkers, and hence, to provide its vital role in diagnosis, prognosis, and treatment of diseases.

\section{Abbreviations}

PTC: Papillary thyroid cancer; KEGG: Kyoto Encyclopedia of Genes and Genomes; mRNA: Messenger ribonucleic acid; NCBI: National Center for Biotechnology Information; GEO: Gene Expression Omnibus;

PI3K: Phosphoinositide 3-kinases; ANOVA: Analysis of variance; TCGA: The Cancer Genome Atlas; RFS: Disease-free rates; OS: Overall survival; FDR: False discovery rate

\section{Acknowledgements}

Not applicable

\section{Authors' contributions}

EA: Collected the data, review of datasets contents, performed the analysis, and draft manuscript preparation. SA: Study design, performed the analysis and discussion, draft manuscript preparation. BS: Conceived and designed the analysis, performed the analysis and discussion, draft manuscript preparation. The authors read and approved the final manuscript.

\section{Funding}

Not applicable

Availability of data and materials

Not applicable

\section{Declarations}

Ethics approval and consent to participate Not applicable 


\section{Consent for publication}

Not applicable

\section{Competing interests}

The authors declare that they have no competing interests.

Received: 22 July 2020 Accepted: 7 May 2021

Published online: 17 May 2021

\section{References}

1. Guo Z, Ge M, Chu Y-H, Asioli S, Lloyd RV. Recent advances in the classification of low-grade papillary-like thyroid neoplasms and aggressive papillary thyroid carcinomas: evolution of diagnostic criteria. Adv Anat Pathol. 2018;25(4):263-72. https://doi.org/10.1097/PAP.0000000000000198.

2. Rossi ED, Pantanowitz L, Hornick JL. A worldwide journey of thyroid cancer incidence centred on tumour histology. Lancet Diab Endocrinol. 2021;9(4): 193-4. https://doi.org/10.1016/\$2213-8587(21)00049-8.

3. Thyroid cancer facts and figures. National Cancer Institute Surveillance, Epidemiology, and End Results Program 2021 [Available from: http://seer.ca ncer.gov/statfacts/html/thyro.html.

4. Song E, Jeon MJ, Oh H-S, Han M, Lee Y-M, Kim TY, et al. Do aggressive variants of papillary thyroid carcinoma have worse clinical outcome than classic papillary thyroid carcinoma? Eur J Endocrinol. 2018;179(3):135-42. https://doi.org/10.1530/EJE-17-0991.

5. Agafonoff S, Allamaneni S, Bernstein J, Braverman T, Naqvi I, Chuchulo A. Hypervascular neck mass as the initial presentation of papillary thyroid cancer: a case report and review of current literature. Int J Surg Case Rep. 2020;66:196-200. https://doi.org/10.1016/j.jjscr.2019.12.010.

6. Aziz NB, Mahmudunnabi RG, Umer M, Sharma S, Rashid MA, Alhamhoom Y, et al. MicroRNAs in ovarian cancer and recent advances in the development of microRNA-based biosensors. Analyst. 2020;145:2038-57.

7. Cai H, Hou X, Ding Y, Fu Z, Wang L, Du Y. Prediction of gastric cancer prognosis in the next-generation sequencing era. Tradit Med Mod Med. 2019;2(3):105-18.

8. Srivastava A, Creek DJ. Discovery and validation of clinical biomarkers of cancer: a review combining metabolomics and proteomics. Proteomics. 2019;19(10):1700448. https://doi.org/10.1002/pmic.201700448.

9. Zaballos MA, Santisteban P. Key signaling pathways in thyroid cancer. J Endocrinol. 2017;235(2):R43-r61. https://doi.org/10.1530/JOE-17-0266.

10. Sharov AA, Schlessinger D, Ko MS. ExAtlas: an interactive online tool for meta-analysis of gene expression data. J Bioinforma Comput Biol. 2015; 13(06):1550019. https://doi.org/10.1142/S0219720015500195.

11. Hong N, Zhang N, Wu H, Lu S, Yu Y, Hou L, et al. Preliminary exploration of survival analysis using the OHDSI common data model: a case study of intrahepatic cholangiocarcinoma. BMC Med Inform Decis Mak. 2018;18(5):81-8.

12. Goel MK, Khanna P, Kishore J. Understanding survival analysis: Kaplan-Meier estimate. Int J Ayurveda Res. 2010;1(4):274-8. https://doi.org/10.4103/09747788.76794

13. Tang Z, Kang B, Li C, Chen T, Zhang Z. GEPIA2: an enhanced web server for large-scale expression profiling and interactive analysis. Nucleic Acids Res. 2019;47(W1):W556-W60. https://doi.org/10.1093/nar/gkz430.

14. de Hoon MJ, Imoto S, Nolan J, Miyano S. Open source clustering software. Bioinformatics. 2004;20(9):1453-4. https://doi.org/10.1093/ bioinformatics/bth078.

15. Ito Y, Miyauchi A, Kihara M, Fukushima M, Higashiyama T, Miya A. Overall survival of papillary thyroid carcinoma patients: a single-institution longterm follow-up of 5897 patients. World J Surg. 2018;42(3):615-22. https:// doi.org/10.1007/s00268-018-4479-z.

16. Franceschi S, Lessi F, Panebianco F, Tantillo E, La Ferla M, Menicagli M, et al. Loss of c-KIT expression in thyroid cancer cells. PLoS One. 2017;12(3): e0173913.

17. Robbins HL, Hague A. The PI3K/Akt pathway in tumors of endocrine tissues. Front Endocrinol. 2016;6:188.

18. Kim M-J, Kim SK, Park HJ, Chung DH, Park H-K, Lee JS, et al. PDGFRA promoter polymorphisms are associated with the risk of papillary thyroid cancer. Mol Med Rep. 2012;5(5):1267-70. https://doi.org/10.3892/ mmr.2012.784.

19. Zhang J, Wang P, Dykstra M, Gelebart P, Williams D, Ingham R, et al. Platelet-derived growth factor receptor-a promotes lymphatic metastases in papillary thyroid cancer. J Pathol. 2012;228(2):241-50. https://doi.org/10.1 002/path.4069.

20. Vella $V$, Malaguarnera $R$. The emerging role of insulin receptor isoforms in thyroid cancer: clinical implications and new perspectives. Int J Mol Sci. 2018;19(12):3814. https://doi.org/10.3390/ijms19123814.

21. Qu T, Li YP, Li XH, Chen Y. Identification of potential biomarkers and drugs for papillary thyroid cancer based on gene expression profile analysis. Mol Med Rep. 2016;14(6):5041-8. https://doi.org/10.3892/mmr.2016.5855.

22. Mitsiades CS, Hayden P, Kotoula V, McMillin DW, McMullan C, Negri J, et al. $\mathrm{BCl}-2$ overexpression in thyroid carcinoma cells increases sensitivity to $\mathrm{BCl}-2$ homology 3 domain inhibition. J Clin Endocrinol Metab. 2007;92(12):484552. https://doi.org/10.1210/jc.2007-0942.

23. Tan J, Qian X, Song B, An X, Cai T, Zuo Z, et al. Integrated bioinformatics analysis reveals that the expression of cathepsin $S$ is associated with lymph node metastasis and poor prognosis in papillary thyroid cancer. Oncol Rep. 2018;40(1):111-22. https://doi.org/10.3892/or.2018.6428.

24. Shin E, Koo JS. Expression of proteins related to autotaxinlysophosphatidate signaling in thyroid tumors. J Transl Med. 2019;17(1):288. https://doi.org/10.1186/s12967-019-2028-7.

25. Cong D, He M, Chen S, Liu X, Liu X, Sun H. Expression profiles of pivotal microRNAs and targets in thyroid papillary carcinoma: an analysis of The Cancer Genome Atlas. OncoTargets Ther. 2015;8:2271.

26. Shang J, Ding Q, Yuan S, Liu J-X, Li F, Zhang H. Network analyses of integrated differentially expressed genes in papillary thyroid carcinoma to identify characteristic genes. Genes. 2019;10(1):45. https://doi.org/10.3390/ genes10010045.

27. Redler A, Di Rocco G, Giannotti D, Frezzotti F, Bernieri MG, Ceccarelli S, et al. Fibroblast growth factor receptor-2 expression in thyroid tumor progression: potential diagnostic application. PLoS One. 2013;8(8):e72224.

28. Kasaian K, Wiseman SM, Walker BA, Schein JE, Zhao Y, Hirst M, et al. The genomic and transcriptomic landscape of anaplastic thyroid cancer: implications for therapy. BMC Cancer. 2015;15(1):984. https://doi.org/10.11 86/s12885-015-1955-9.

29. Jhunjhunwala S, Jiang Z, Stawiski EW, Gnad F, Liu J, Mayba O, et al. Diverse modes of genomic alteration in hepatocellular carcinoma. Genome Biol. 2014;15(8):436. https://doi.org/10.1186/s13059-014-0436-9.

30. Zhang Y, Li F, Chen J. MYC promotes the development of papillary thyroid carcinoma by inhibiting the expression of IncRNA PAX8-AS1: 28. Oncol Rep. 2019;41(4):2511-7. https://doi.org/10.3892/or.2019.6996.

31. Huang W, Gu J, Tao T, Zhang J, Wang H, Fan Y. MiR-24-3p inhibits the progression of pancreatic ductal adenocarcinoma through LAMB3 downregulation. Front Oncol. 2020;9:1499. https://doi.org/10.3389/fonc.2 019.01499 .

32. Han J, Chen M, Wang Y, Gong B, Zhuang T, Liang L, et al. Identification of biomarkers based on differentially expressed genes in papillary thyroid carcinoma. Sci Rep. 2018;8(1):1-11.

33. Hosseinkhan N, Honardoost M, Blighe K, Moore C, Khamseh M. Comprehensive transcriptomic analysis of papillary thyroid cancer: potential biomarkers associated with tumor progression. J Endocrinol Investig. 2020;43(7):911-23.

34. Qiu J, Zhang W, Xia Q, Liu F, Zhao S, Zhang K, et al. Investigating the mechanisms of papillary thyroid carcinoma using transcriptome analysis. Mol Med Rep. 2017;16(5):5954-64. https://doi.org/10.3892/mmr.2017.7346.

35. Schulten $\mathrm{H}-J$, Alotibi R, Al-Ahmadi A, Ata M, Karim S, Huwait E, et al. Effect of BRAF mutational status on expression profiles in conventional papillary thyroid carcinomas. BMC Genomics. 2015;16(S1):S6. https://doi.org/10.11 86/1471-2164-16-S1-S6.

36. Kato S, Kobayashi T, Yamada K, Nishii K, Sawada H, Ishiguro H, et al. Expression of erbB receptors mRNA in thyroid tissues. Biochim Biophys Acta. 2004;1673(3):194-200

37. Sun J, Shi R, Zhao S, Li X, Lu S, Bu H, et al. E2F8, a direct target of miR-144, promotes papillary thyroid cancer progression via regulating cell cycle. J Exp Clin Cancer Res. 2017;36(1):40. https://doi.org/10.1 186/s13046-017-0504-6.

38. Kim MK, Park SW, Kim SK, Park HJ, Eun YG, Kwon KH, et al. Association of Toll-like receptor 2 polymorphisms with papillary thyroid cancer and clinicopathologic features in a Korean population. J Korean Med Sci. 2012; 27(11):1333-8. https://doi.org/10.3346/jkms.2012.27.11.1333.

39. Leone V, D'Angelo D, Rubio I, de Freitas PM, Federico A, Colamaio M, et al. MiR-1 is a tumor suppressor in thyroid carcinogenesis targeting CCND2, CXCR4, and SDF-1a. J Clin Endocrinol Metab. 2011;96(9):E1388-E98. https:// doi.org/10.1210/jc.2011-0345. 
40. Zhu W, Li C, Ai Z. Candidate agents for papillary thyroid cancer identified by gene expression analysis. Pathol Oncol Res. 2013;19(3):597-604. https://doi. org/10.1007/s12253-013-9625-1.

41. Yamashita AS, Geraldo MV, Fuziwara CS, Kulcsar MAV, Friguglietti CUM, da Costa RB, et al. Notch pathway is activated by MAPK signaling and influences papillary thyroid cancer proliferation. Transl Oncol. 2013;6(2):197. https://doi.org/10.1593/tlo.12442.

42. Lee K-Y, Huang SM, Li S, Kim J-M. Identification of differentially expressed genes in papillary thyroid cancers. Yonsei Med J. 2009;50(1):60-7. https:// doi.org/10.3349/ymj.2009.50.1.60.

43. Liang W, Sun F. Identification of key genes of papillary thyroid cancer using integrated bioinformatics analysis. J Endocrinol Investig. 2018;41(10):123745. https://doi.org/10.1007/s40618-018-0859-3.

44. Lee EJ, Gusev Y, Jiang J, Nuovo GJ, Lerner MR, Frankel WL, et al. Expression profiling identifies microRNA signature in pancreatic cancer. Int J Cancer. 2007;120(5):1046-54. https://doi.org/10.1002/ijc.22394.

45. LV Y, Huang S. Role of non-coding RNA in pancreatic cancer. Oncol Lett. 2019;18(4):3963-73. https://doi.org/10.3892/ol.2019.10758.

46. Boedigheimer MJ, Wolfinger RD, Bass MB, Bushel PR, Chou JW, Cooper M, et al. Sources of variation in baseline gene expression levels from toxicogenomics study control animals across multiple laboratories. BMC Genomics. 2008:9(1):285. https://doi.org/10.1186/1471-2164-9-285.

47. Shinohara M, Chung YJ, Saji M, Ringel MD. AKT in thyroid tumorigenesis and progression. Endocrinology. 2007;148(3):942-7. https://doi.org/10.1210/ en.2006-0937.

48. Xu Y, Han Y-F, Zhu S-J, Dong J-D, Ye B. miRNA-148a inhibits cell growth of papillary thyroid cancer through STAT3 and PI3K/AKT signaling pathways. Oncol Rep. 2017;38(5):3085-93. https://doi.org/10.3892/or.2017.5947.

\section{Publisher's Note}

Springer Nature remains neutral with regard to jurisdictional claims in published maps and institutional affiliations.

\section{Submit your manuscript to a SpringerOpen ${ }^{\circ}$ journal and benefit from:}

- Convenient online submission

- Rigorous peer review

- Open access: articles freely available online

High visibility within the field

- Retaining the copyright to your article

Submit your next manuscript at $\boldsymbol{\nabla}$ springeropen.com 